\title{
Drug-drug interactions and QT prolongation as a commonly assessed cardiac effect - comprehensive overview of clinical trials
}

\author{
Barbara Wiśniowska ${ }^{1 *}$, Zofia Tylutki ${ }^{1}$, Gabriela Wyszogrodzka ${ }^{2}$ and Sebastian Polak ${ }^{1,3}$ (1)
}

\begin{abstract}
Background: Proarrhythmia assessment is one of the major concerns for regulatory bodies and pharmaceutical industry. ICH guidelines recommending preclinical tests have been established in attempt to eliminate the risk of drug-induced arrhythmias. However, in the clinic, arrhythmia occurrence is determined not only by the inherent property of a drug to block ion currents and disturb electrophysiological activity of cardiac myocytes, but also by many other factors modifying individual risk of QT prolongation and subsequent proarrhythmia propensity. One of those is drug-drug interactions. Since polypharmacy is a common practice in clinical settings, it can be anticipated that there is a relatively high risk that the patient will receive at least two drugs mutually modifying their proarrhythmic potential and resulting either in triggering the occurrence or mitigating the clinical symptoms. The mechanism can be observed either directly at the pharmacodynamic level by competing for the molecular targets, or indirectly by modifying the physiological parameters, or at the pharmacokinetic level by alteration of the active concentration of the victim drug.

Methods: This publication provides an overview of published clinical studies on pharmacokinetic and/or pharmacodynamic drug-drug interactions in humans and their electrophysiological consequences (QT interval modification). Databases of PubMed and Scopus were searched and combinations of the following keywords were used for Title, Abstract and Keywords fields: interaction, coadministration, combination, DDI and electrocardiographic, QTC interval, ECG. Only human studies were included. Over 4500 publications were retrieved and underwent preliminary assessment to identify papers accordant with the topic of this review. 76 papers reporting results for 96 drug combinations were found and analyzed.
\end{abstract}

Results: The results show the tremendous variability of drug-drug interaction effects, which makes one aware of complexity of the problem, and suggests the need for assessment of an additional risk factors and careful ECG monitoring before administration of drugs with anticipated QT prolongation.

Conclusions: DDls can play significant roles in drugs' cardiac safety, as evidenced by the provided examples. Assessment of the pharmacodynamic effects of the drug interactions is more challenging as compared to the pharmacokinetic due to the significant diversity in the endpoints which should be analyzed specifically for various clinical effects. Nevertheless, PD components of DDls should be accounted for as PK changes alone do not allow to fully explain the electrophysiological effects in clinic situations.

Keywords: QT prolongation, Drug-drug interactions, Clinical trials

\footnotetext{
* Correspondence: b.wisniowska@uj.edu.pl

${ }^{1}$ Unit of Pharmacoepidemiology and Pharmacoeconomics, Department of

Social Pharmacy, Faculty of Pharmacy, Jagiellonian University Medical

College, Medyczna 9 Street, 30-688 Krakow, Poland

Full list of author information is available at the end of the article
}

\section{Ciomed Central}

C 2016 Wiśniowska et al. Open Access This article is distributed under the terms of the Creative Commons Attribution 4.0 International License (http://creativecommons.org/licenses/by/4.0/), which permits unrestricted use, distribution, and reproduction in any medium, provided you give appropriate credit to the original author(s) and the source, provide a link to the Creative Commons license, and indicate if changes were made. The Creative Commons Public Domain Dedication waiver (http://creativecommons.org/publicdomain/zero/1.0/) applies to the data made available in this article, unless otherwise stated. 


\section{Background}

Cardiovascular toxicity remains one of the leading causes of early and late attrition during the drug development process as well as a major contributor to withdrawals of marketed drugs [1-3]. Cardiac safety concerns arise from a variety of side effects of the drugs including, but not limited to, direct myocyte injury, activation of apoptotic and necrotic changes, alternation of ion homeostasis or the signaling pathways or influence on the transcription factors i.e. kinase inhibitors $[4,5]$. Though, proarrhythmia represents one of the most frequent cardiac safety liabilities responsible for cardiotoxic effect especially in the late stage of clinical development and during post-marketing surveillance [6]. The most important drug-induced form of proarrhythmia is acquired long QT syndrome (LQTS) and resulting potentially fatal polymorphic ventricular tachycardia termed torsades de pointes (TdP).

Tremendous progress has been made in research on and understanding of mechanisms underlying QT prolongation and TdP risk since the 1920s when quinidine syncope was first recognized. Quinidine was introduced to the practice as an antiarrhythmic for patients with atrial fibrillation [7]. Soon thereafter reports of sudden, occasionally fatal syncopal episodes occurring within therapy initiation period began to appear. It was not until the advent of online electrocardiographic monitoring that the ventricular tachyarrhythmia was described as the cause of "quinidine syncope" phenomenon in 1964 by Seltzer and Wray [8]. Characteristic for quinidine polymorphic arrhythmia was later observed by Dessertenne in a patient with atrio-ventricular block [9]. To describe his observations, twisting QRS complex around the isoelectric line on the surface ECG, he coined the term "torsades de pointes". Interestingly, both of these early reports neither highlighted nor commented on prolonged QT interval, which was then observed in patients who were reported in the late 1970s to have developed TdP. Since that time much effort has been invested in elucidation of mechanism of drug-induced TdP and despite some reservations QT prolongation is currently recognized as an underlying cause of development of the TdP arrhythmia and thus major focus of drug development and a significant concern for regulatory agencies [10]. It is well known that QT prolongation is not directly correlated with $\mathrm{TdP}$ occurrence and ventricular fibrillation. Regardless of the reservations to the predictability of this marker and growing awareness of its imperfection, QT interval prolongation is still most commonly used in vivo surrogate of the proarrhythmic potency of drugs (ICH E14 guidelines). Prolongation of the repolarization process, reflected by long QT in ECG, can result from a net reduction in the outward current due to either decreased outward potassium currents (IKr or IKs), or activation of a delayed sodium current, or an increased inward calcium current [11-14].
However, most cases of prolonged repolarization related to drug exposure can be traced to the inhibition of hERG (human ether-a-go-go-related gene) potassium channel regulating major repolarizing current in the heart, $\mathrm{IKr}$ [15-17]. Therefore during non-clinical phase of drug development the concentration of the tested substance producing half-maximal block of the hERG potassium current (IC50) is an in vitro surrogate for proarrhythmic propensity of a compound. The class III antiarrhythmics, for which hERG inhibition underlie in part therapeutic mechanism of action, are found to carry the highest risk of TdP, estimated incidence in general population of $5 \%$ [18]. Yet, inherent property of hERG channel is the ability to bind and interact with diverse chemical structures that encompass several therapeutic classes, including, apart from antiarrhythmics, antibiotics, prokinetics, antipsychotics and antihistamines [19, 20]. The TdP risk for non-cardiac drugs is generally estimated to be in the range of $<0.01 \%$ up to $0.1 \%$, however in patients certain drugs e.g. dofetilide (anthiarrhythmic) in high doses it can be as high as $10.5 \%$ [21]. Moreover, most of these drugs which are used for the symptomatic treatment of rather benign conditions, are more frequently prescribed with hardly any ECG monitoring $[22,23]$. Upon the results of the survey conducted by De Ponti et al. it is estimated that up to $3 \%$ of patients in the UK and Italy are prescribed at least one noncardiac drug with proarrhythmic propensity supported by published data and official warnings about QT prolongation or TdP occurrence [24]. Estimates made by Curtis and colleagues [25] are even higher. Authors conducted retrospective study and analyzed QT-prolonging drugs prescribed with the use of outpatient prescription claims database of the largest pharmaceutical benefit in the United States and concluded that over 1 million out of about 5 million patients cohort use at least $1 \mathrm{QT}$ prolonging medication ( $\sim 23 \%$ of patients). This can explain a great deal of attention and significant efforts put into the understanding, detailed screening and governing of the potential proarrhythmic potency of novel drugs by the regulatory (ICH S7 and ICH E14 guidelines), academia and industry worldwide (ICH S7 E14 guidelines).

Additionally, the problem of acquired QT prolongation and TdP is further complicated in patients undergoing polytherapy. Since polypharmacy is a common practice in clinical settings, it can be anticipated that there is a relatively high risk that a patient will receive at least two drugs mutually modifying their proarrhythmic potential and resulting in clinical symptoms or mitigating symptoms connected with one of them [22, 26-29]. In the study by Curtis and colleagues in a cohort of 1.1 million patients the concomitant use of 2 QT prolonging agents was identified in $9.4 \%$ of patients, and the use of $\geq 3$ agents in $0.7 \%$ of patients. Indeed, clinical cases of $\mathrm{TdP}$ are frequently related 
to polypharmacy and drug-drug interaction resulting in QT interval prolongation [25] The results of retrospective analysis of FDA AERS (Food and Drug Administration Adverse Event Reporting System) database by Shaffer et al., where concomitant risk factors for QT prolongation and TdP occurring in association with administration of macrolide antimicrobials were examined, pointed out that coadministration of drug prolonging QT interval accounts for $50 \%$ of registered TdP reports [30].

In populations receiving multiple medications potential drug-drug interactions (DDIs) are of major concern, therefore the topic has received much attention and some formal approaches have been established. However, they concern only pharmacokinetic (PK) interactions occurring due to alterations in drug metabolism or disposition, while assessment of pharmacodynamic (PD) interactions is hardly possible due to character of the effects of such endpoints which are serious adverse effects rather than measurable changes in drug concentration [31]. Although the incidence of clinically significant PD interactions is much lower than that of PK interactions, they should not be underestimated since they can be of great importance for patient safety [32]. In case of TdP arrhythmia QT interval prolongation can be used as a relatively safe indicator of PD drug interaction result, though a number of drug combinations possibly implicated in QT prolongation is practically infinite and it is infeasible to comprehensively assess all of them during the drug development process and clinical trials. Additionally significant diversity in the study design, clinical endpoints analysis, studied populations and other factors make the PD component of DDIs challenging to analyze. Terfenadine can be used as an example due to multiple available studies clearly showing wide range of clinical endpoints, in this case QT prolongation. Figure 1 presents results of five studies where terfenadine was given either alone or concomitantly with different CYP 3A4 inhibitors. One can note obvious QT prolongation which on one hand side proves the role of DDI, yet at the same time significant variability in the effect for both scenarios (with and without inhibitor) can be also seen.

\section{The aim of the study}

This publication provides an overview of published clinical studies results on pharmacokinetic and/or pharmacodynamic drug-drug interactions in humans (either healthy volunteers or patients) and their electrophysiological consequences manifested as change in the QT/QTc interval. The main aim was to present the role and potential clinical relevance of drug combinations for cardiac safety as evidenced in clinical trials. We aimed in presenting of the diversity of parameters influencing the electrophysiological effects of drug combinations in clinic situations; the specific statistical analysis was neither planned nor conducted.

\section{Methods}

Databases of PubMed and Scopus were searched through November 2014 without time limit. Combinations of the following keywords were used for Title, Abstract and Keywords fields: interaction, coadministration, combination, DDI and electrocardiographic, QTc interval, ECG. Only human studies were included. Over 4500 publications were retrieved and underwent preliminary assessment to identify papers accordant with the topic of this review. Inclusion criteria met only articles describing clinical studies where the effects of two or more agents given concomitantly on the QT interval length were analyzed. All case study reports were excluded from the analysis. Reference lists from the eligible papers were the additional source of publications included in this review. Studies on combinations of antiarrhythmic drugs where their effect on QT interval was not of primary concern, and pharmacokinetics of involved compounds was out of their scope, were considered as not eligible for this review. Finally, we found 76 publications to be eligible for this review. They were divided into several groups, primarily according to the compound defined as victim drug in a clinical trial.

The results of the presented literature review are divided into two parts: 1) general description of drug classes studied for the effects of their combinations with metabolic inhibitors or other agents which might be given concomitantly; and 2) tabularized description of studies protocols, participants, PK and/or PD changes. The latter is provided as the Additional file 1: Table S1.

\section{Results}

\section{Antiarrhythmics}

Antiarrhythmics were the first drugs associated with QT interval prolongation and ventricular arrhythmia with the quinidine being most frequently implicated with the estimated TdP incidence in patients treated ranging from 1 to $8.8 \%$ or even $28 \%$ in certain groups [18]. Treatment of disorders of cardiac rhythm often requires polytherapy with antiarrhythmic drugs, many of which undergo cytochrome CYP450 metabolism. They may be inhibitors or inducers of CYP enzymes. For this reason PK and PD interactions between antiarrhythmic compounds can be of clinical importance in terms of efficacy and toxicity, especially for compounds with narrow therapeutic range, e.g. quinidine, digoxin, flecainide. Several studies involving antiarrhythmic drugs had been identified. Their results indicate that multidrug regimens may improve treatment efficacy and safety if chosen properly. On the other hand, they point out the fact that knowledge of existing and plausible drug interactions is essential to optimize therapy for individual patients. 


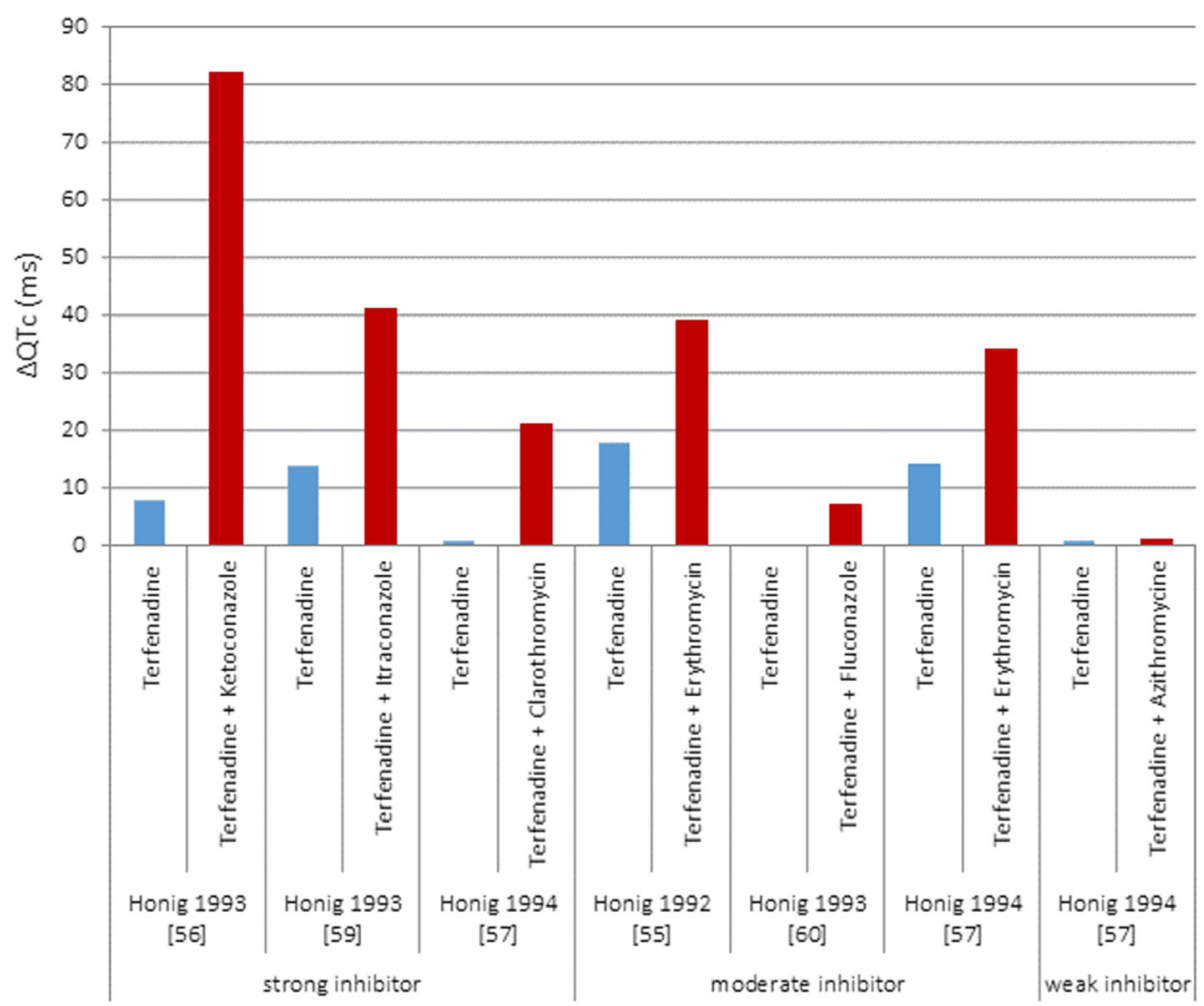

Fig. 1 Results of five clinical studies with terfenadine given either alone or concomitantly with different CYP 3A4 inhibitors

Twelve published reports from clinical trials were identified for antiarrhythmic drugs. Tartini and Kappenberger described excessive prolongation of QT interval and development of torsades de pointes arrhythmia in two patients treated with a combination of quinidine and amiodarone for minor arrhythmia [33]. The interaction was confirmed in a 33-year-old male healthy volunteer. Amiodarone caused significant elevation of quinidine concentration ( $90 \%$ increase of $C_{\max }$ ) which led to substantial (41 \% as compared to baseline) prolongation of QT interval [34]. The need for careful ECG and quinidine concentrations monitoring was concluded. On the contrary, subsequent administration of verapamil may have a protective effect against quinidine-related TdP arrhythmia. In the study described by Theisen and Scheininger [35] verapamil i.v. was shown to slightly $(10 \mathrm{~ms})$ but significantly shorten prolonged QTc interval supervene as a result of quinidine i.v. administration without lowering quinidine efficacy in a slowing flutter rate and conversion of atrial fibrillation. In most studies considering quinidine interactions it was used rather as a perpetrator than victim drug and possible victim drug toxicity or lack of its effectiveness were of primary concern instead of quinidine cardiotoxicity. In the study aimed at determining whether calcium antagonists interact with digoxin and influence its glycoside effects, quinidine $(250 \mathrm{mg}$ t.i.d.) induced substantial increase (118\%) in digoxin concentration [36].
The above resulted in intensification of digoxin glycoside effects and attenuation of its QTc shortening effect. Other compounds tested, namely verapamil, gallopamil, propafenone and nifedipine, amplified digoxin concentration to a lesser extent (16-77 \%) and further shortened QTc interval. Two further studies investigated a role of quinidine, as a potent inhibitor of the genetically-determined debrisoquine 4-hydroxylation (CYP 2D6), in the interactions with propafenone and propranolole [37, 38].

Both studies showed significant elevations of victim drugs concentrations: propafenone mean steady-state plasma concentration increased by $169 \%$ in a group of extensive metabolizers (no change in 2 poor metabolizing subjects) and propranolol AUC (area under the plasma drug concentration-time curve) by $92 \%$, moreover, the effect was stereoselective. In Funck-Brentano study despite changes in propafenone plasma concentration induced by low dose of quinidine $(50 \mathrm{mg}$ ) electrophysiological parameters remained unaltered. The same dose of quinidine administered with propranolole resulted in QTc interval prolongation (up to $29 \mathrm{~ms}$ ) which may be of therapeutic importance. However, explanation for this was unclear since neither propranolole nor quinidine produced delay of repolarization process when given alone. Changes in quinidine or its metabolites (not studied) and effects of propranolole and its metabolites on ventricular repolarization are among suggested explanations. 
Increased arrhythmia risk is also reported to be related to high concentrations of flecainide, metabolized by the cytochrome P450 2D6 izoenzyme antiarrhythmic agent with relatively narrow therapeutic range. This gave an incentive for a study of flecainide interaction with amiodarone, a weak inhibitor of cytochrome CYP 2D6 among healthy volunteers with polymorphism of CYP 2D6 [39-41]. The study in healthy Caucasian population by Funck-Brentano et al. failed to find significant differences between flecainide concentrations in both CYP 2D6 phenotypes (poor and extensive metabolizers). Significant ECG changes were observed at flecainide dosage of $100 \mathrm{mg}$ b.i.d. but not at dosage of $50 \mathrm{mg}$ b.i.d., the extent of changes was similar in both phenotypes. Combination with amiodarone resulted in significant increase in flecainide plasma concentration and more pronounced QTcF (Fridericia's correction) change in both, extensive and poor metabolizers. Similarly to administration of flecainide alone, the extent of QTcF interval prolongation did not differ significantly between the groups. Dosage adjustment for flecainide was suggested if amiodarone is to be co-administered. These results differ from those reported for population of diseased infants, where both effectiveness and safety of combined flecainide and amiodarone in refractory tachyarrhythmias were demonstrated [42]. Fenrich and colleagues declare concordance of their findings with other studies conducted in adult patients with supraventricular and ventricular tachycardia. Similarly to Funck-Brentano study, Lim et al. did not find any significant differences in flecainide $C_{\max }$ at both occasions, namely administration of flecainide alone or in combination with paroxetine, between study groups of healthy Korean male subjects genetically determined as extensive (EM), intermediate (IM), and poor metabolizers (PM) [41]. QTc intervals at baseline were comparable in all 3 groups, significant increases from time-matched baseline in the QTc intervals were found in all genotype groups following flecainide administration. The extent of additional QTc prolongation, when paroxetine was added, was similar (about $6 \mathrm{~ms}$ ) and statistically significant in EM and IM subjects. QTc prolongation in PM was less pronounced $(3.9 \mathrm{~ms})$. Quantitatively QTc changes in study groups did not correspond with AUC changes, and large interindividual pharmacodynamic variability is suggested as an explanation of this situation. Authors conclude that plasma flecainide concentration determination may be an insufficient predictor of electrophysiologic changes [40].

Another antiarrhythmic drug which can be used in combinations and tested for its electrophysiological consequences was tedisamil. Tedisamil, as a bradycardic agent can be used in patients with angina pectoris either alone or in combination with other anti-anginal drugs thus Demolis et al. designed and conducted a study aiming in evaluation of its effects on heart rate and QT interval duration either alone or in combination with atenolol [43]. Tedisamil, but not atenolol, prolonged QT intervals in study subjects. Observed prolongation was reverse rate-dependent as QT prolongation was much less pronounced at high rather than at low heart rates. This correlation remained unchanged during combined therapy with atenolol. Moreover, since the extent of QT prolongation during concomitant administration of atenolol and tedisamil was similar to those observed in monotherapy the authors state that there is no additional risk arising from the combination of atenolol and tedisamil.

Quinidine, a class IA antiarrhythmic agent was also tested in combination used in the therapy of condition not related with heart rhythm disorders. In the therapy of pseudobulbar affect (PBA) dextromethorphan is coadministered with low quinidine doses. While quinidine doses are of orders of magnitude lower than those for arrhythmia treatment, $20-30 \mathrm{mg}$ vs $800-2400 \mathrm{mg}$ [44], the related risk of QT interval should be negligible, however, during clinical trials investigating efficacy of dextromethorphan-quinidine combination in PBA [45-48] patients were monitored for electrophysiological abnormalities. The results proved the assumption on safety of low-dose quinidine therapy.

\section{Antihistamines}

Terfenadine and astemizole were the first second-generation, non-sedating antihistamines. When launched to the market they were considered as a great breakthrough in the allergy pharmacotherapy. However, enthusiasm for them was hampered soon after by the case reports on torsades de pointes [49-52]. A growing number of alarming reports on terfenadine-related QT prolongations and TdP cases prompted the FDA to ask its manufacturer to withdraw the drug due to concerns about potential of the cardiac arrhythmias and patients sudden deaths, especially because a new, safer alternative - fexofenadine was approved. About a year later Johnson \& Johnson voluntarily withdrew astemizole from the global market. The data from both astemizole and terfenadine adverse event reports submitted via the FDA AERS allowed to conclude that ventricular arrhythmia was associated with substantially elevated plasma concentrations of these drugs, resulting from the drug-drug interactions preventing its metabolic degradation, hepatic impairment, or overdose $[53,54]$. This urged clinical studies that were about to test the hypothesis on the role of metabolic inhibition and pharmacokinetic changes in a QT interval prolongation following astemizole and terfenadine administration.

Honig and colleagues published a series of papers upon their research investigating terfenadine interaction with well-known inhibitors of hepatic oxidative metabolism, namely erythromycin, clarithromycin and ketoconazole, which may be co-administered [55-57]. 
They also conducted a study for a new at that time antifungal agents: itraconazole and fluconazole, which both demonstrate weaker in vitro inhibition of CYP enzymes than ketoconazole $[34,58]$, in order to investigate the magnitude of probably less pronounced but still plausible interaction [59,60]. The aim of all the studies was to examine the influence of DDIs on terfenadine $\mathrm{PK}$ and its pharmacodynamic consequences represented by electrocardiographic changes. Six to nine healthy subjects, both female and male, were enrolled for each particular study. During terfenadine monotherapy (first study phase), only some individuals had detectable terfenadine concentrations (limit of quantification in plasma, LoQ $-5 \mathrm{ng} / \mathrm{mL}$ ), while inhibitor was added, levels of unmetabolized terfenadine increased above LoQ depending on its CYP 3A4 blocking potency. Accordingly, fluconazole (moderate inhibitor) and azithromycin (weak inhibitor) did not cause any significant PK changes nor accumulation of the unmetabolized terfenadine. The results for azithromycin were confirmed by Harris and colleagues in 1995 [61]. In this study none of the subjects had detectable ( $>10 \mathrm{ng} / \mathrm{mL}$ ) terfenadine plasma level throughout the whole study period. Two further studies investigated terfenadine DDI with fluoxetine and paroxetine [62, 63]. In all the studies after administration of terfenadine the QTc interval was prolonged on average by 1 to $18 \mathrm{~ms}$ as compared to baseline. As a consequence of changed exposure, mean QTc increased from 1 to $82 \mathrm{~ms}$ (azithromycin and ketoconazole) across the studies.

Another study investigated terfenadine interaction with an antidepressant nefazodone [64], which has been shown to selectively inhibit cytochrome CYP 3A4 enzymes in clinical doses [65]. Terfenadine $C_{\max }$ and $A U C$ were markedly increased with concomitant administration of nefazodone. As expected, interaction resulted in the significant QTc intervals prolongation when compared to baseline. Two further studies investigated the PD component of interaction with terfenadine [66, 67]. They both involved sparfloxacin, a broad-spectrum fluoroquinolone antibiotic pre-clinically and clinically shown to cause dose-dependent QT interval prolongation. In a group of healthy men volunteers pharmacokinetics of sparfloxacin remained unchanged after addition of terfenadine during study by Morganroth et al. [66]. Akhtar and colleagues did not investigate PK either for terfenadine or for sparfloxacin [67]. There was no significant increase in the QTc duration in the terfenadine-treated subjects in both studies. A combination therapy was found to be connected with additive effect of concomitantly administered drugs on the QTc length.

A significant interindividual variability in ECG response to altered parent terfenadine concentrations was demonstrated in all of the above presented studies, suggesting a large role of physiological and genetic factors accounting for individual susceptibility to a QT prolongation and cardiac arrhythmia occurrence. Furthermore, substantial variability of inhibitor effect on terfenadine concentrations was observed in all studies. This may be due to the differences between subjects affecting bioavailability of the drugs or genetically determined diverse levels of CYP450 3A4 expression as well as different CYP inhibitory potencies of ketoconazole, itraconazole and erythromycin. It has been suggested that function of P-gp or OATP transporters altered by concomitantly administered drugs may influence the disposition of victim drugs, however, an interindividual variation in drug transporter expression further complicates predictions of the interaction effects in a population [68-71].

Also a single report on the effects of co-administration of terfenadine metabolite (fexofenadine) with azithromycin was found [72]. As opposed to results of terfenadineazithromycin study, in this study co-administration of both drugs in a population of healthy volunteers resulted in substantial increase of fexofenadine bioavailability, however, it did not lead to any statistically significant or clinically relevant changes in ECG (QTc interval prolonged by $1.4 \mathrm{~ms})$.

Astemizole interactions were investigated in two studies $[73,74]$. Itraconazole, unlike dirithromycine, significantly increased astemizole systemic exposure. However, a QT interval change was not observed in any of the studies. Nevertheless, authors strongly suggest avoidance of concomitant administration of astemizole and itraconazole because of possible differences between single dose study results and chronic astemizole intake and anticipated effect of observed in the Lefebvre study astemizole clearance reduction for prolonged astemizole therapy [74]. Also Bachmann advised further investigation of electrophysiological consequences for astemizole interaction proposing study with different design, however, since Johnson \& Johnson withdrew astemizole from the market two years after Lefebvre and Bachmann studies, and according to our best knowledge, no additional investigations with publicly available results were carried out [73].

The awareness that the cardiotoxicity is not a class effect of antihistamines, yet their administration can induce the QT prolongation and in certain circumstances be potentially proarrhythmic prompted further studies aimed at assessment of individualized risk for some antihistaminic compounds. One of the drugs extensively studied for its interactions and their electrocardiographic effects is loratadine with its active metabolite desloratadine.

Four papers reporting five clinical trials with loratadine administered concomitantly with CYP enzymes inhibitors having different inhibitory profiles were identified [75-78]. The influence of potent CYP 3A4 (clarithromycin, ketoconazole, nefazodone), moderate CYP 3A4 (erythromycin), 
and weak CYP 3A4 and 2D6 (cimetidine) inhibitors, according to the FDA classification [34], on loratadine PK had been studied. The data from those studies demonstrated anticipated effects of applied inhibitors on the clearance of both loratadine and desloratadine. Despite the observed differences between magnitude of the pharmacokinetic interactions of loratadine with diverse CYP inhibitors the pharmacodynamic consequences were principally the same. The tested drug combinations were safe and well tolerated. The mean QTc interval changes for drug combinations were not significantly different from the increase accompanying co-administration of inhibitors with placebo. The results of majority of studies suggest that loratadine does not share the proarrhythmic potential of other nonsedating antihistamines, in particular terfenadine, and considering the wide safety margin of loratadine its interactions with CYP inhibitors are probably clinically unimportant.

Safety profile of desloratadine, a major metabolic derivative of loratadine, has been confirmed in three independent clinical studies with both recommended clinical and supratherapeutic dose in healthy volunteers [72, 79-82]. It was demonstrated that despite induced by ketoconazole, erythromycin, and azithromycin, higher desloratadine exposure, the co-medications were well tolerated and caused neither significant QTc interval prolongation nor changes in adverse events profile. The authors unanimously concluded that desloratadine combinations with CYP inhibitors are safe and may be administered to the patients without concerns about clinically significant cardiac events.

Tyl and colleagues report on results of the ICH E14 guideline compliant thorough QT/QTc study for a bilastine [83]. It was shown that bilastine at therapeutic and supratherapeutic doses don't have any impact on QTc intervals measured in healthy volunteers. Co-administration with ketoconazole resulted in an increased bilastine bioavailability and resulted in increased systemic exposure. Clinically significant increase in QTc intervals duration was observed, however, this was most likely related to ketoconazole effect alone, as bilastine concentrations did not exceed those during supratherapeutic doses administration and no correlation between bilastine PK and QTc was found.

The results of studies concerning antiallergics show that the actual QT prolongation differs substantially between individuals, and is dependent not only on hERG inhibition potential of the agent and metabolic interactions resulting from polytherapy but also other stages of ADME process can significantly influence proarrhythmia risk.

\section{Gastrointestinal prokinetic agents}

Cisapride, a gastric pro-motility agent indicated for gastro-oesophageal reflux disease treatment, is another, after terfenadine and astemizole, hallmark example of market withdrawal of non-cardiac blockbuster drug due to unacceptable risk of a QT interval prolongation and
$\mathrm{TdP}$ arrhythmia. Cisapride was removed from the global market [84] as a consequence of several case reports of major cardiac toxicity, following analysis of the FDA AERS database by Wysowski et al. 2001 [85] and a casecontrol study [86] which provided evidence that cisapride is associated with the increased occurrence of the QT prolongation, ventricular arrhythmia and sudden cardiac death. It is worth noted that apart from the drug related characteristics Wysowski noticed the role of other factors influencing cisapride clinical effect, including but not limited to certain health conditions (i.e. heart diseases, electrolytes disorder). However, in spite of its withdrawal, cisapride is still available in the U.S. through an investigational program to patients who meet certain criteria since it is considered to be the most effective agent for gastric motility, as well as in some European countries. Administration of cisapride alone is known to be a cause of the QT prolongation [87-90]. However, many of the adverse reactions ascribed to cisapride occurred in patients with conditions that could predispose to cardiac arrhythmias or taking other drugs that inhibit cisapride metabolism via CYP 3A4 enzymes or prolong QT interval [91]. The increased risk following metabolic inhibition and co-administration of other QTprolonging drug was demonstrated by van Haarst [92] and Zix [93]. Interestingly, concomitant therapy with clarithromycin caused substantially greater change in the QTc interval duration than would be expected from simple additive effect of both drugs. Due to hERG blocking properties of both drugs [94] it was conceivable that PD interactions may occur with this combination. Nonetheless, van Haarst study design did not allow for quantitative assessment of PK and PD component contribution in this interaction, but dependence of the QTc intervals on cisapride concentration was observed what suggests an overriding role of PK component in the overall electrophysiological effect. The second study investigated the clinical relevance of possible cisapride interaction with QT-prolonging drug - sparfloxacin. Considering that, as it was proven in the study, cisapride has no influence on sparfloxacin PK and assuming that there is no influence of sparfloxacin on cisapride PK, the observed QTc prolongation can be ascribed to PD interaction only. Nevertheless, reported results do not allow to assess whether the type of the interaction is additive or synergistic.

Cisapride has narrow therapeutic index thus even weak inhibition of CYP mediated metabolism and consequent modest concentration increase is potentially important. As depression and gastroesophageal reflux disease often occur together and many of SSRI (selective serotonin reuptake inhibitors) demonstrate some extent of CYP inhibitory properties, it is important to determine whether potentially harmful interactions occur between antidepressants and cisapride. In the two identified studies fluoxetine 
[95] and sertraline [96] were studied for effects of their interaction with cisapride. Data from both studies indicate that cisapride can be safely administered to patients who are treated with fluoxetine and sertraline while neither fluoxetine nor cisapride, nor sertraline, nor their combination induced statistically or clinically significant ECG parameters change. This was due to decreased cisapride concentrations caused by both drugs. For sertraline the above is in accordance with the results of studies concluding that it is a weak inducer of CYP enzymes [97, 98], however for fluoxetine reasons for such an effect are unclear, while fluoxetine with its active metabolite, norfluoxetine, are inhibitors of CYP P450 system enzymes [99].

Two newer, more selective (as compared to cisapride) 5-HT4 receptor agonists were studied for their cardiac safety under conditions known to favor arrhythmia development with cisapride, namely CYP mediated metabolism inhibition [27, 100, 101]. The results of both studies indicate that neither mosapride nor cinitapride itself carry proarrhythmic potential since they did not produce any changes in the electrocardiograms. Also, there was no significant correlation between plasma concentrations of both drugs and QTc intervals. Moreover, concomitant administration with potent CYP inhibitors, ketoconazole and erythromycin, resulted in only slight increases in plasma concentrations of victim drugs, though without any clinically significant changes in electrocardiographic findings.

Boyce and colleagues designed a study to assess the PK and electrophysiological effects of domperidone and ketoconazole, an agent influencing domperidone metabolism and P-gp dependent disposition, and the consequences of their interaction in healthy volunteers [26]. Ketoconazole significantly increased domperidone plasma concentrations in all subjects, however observed PD effects were strongly dependent on gender, and were more pronounced in men, for both compounds given alone and their combination. Based on the results the authors conclude that domperidone and ketoconazole should not be administered concomitantly.

\section{Antiemetics}

Droperidol (dopamine D2 receptor antagonist) and ondansetron (serotonine 5-HT3 receptor antagonist) are the first-line antiemetics for prevention and treatment of postoperative nausea and vomiting (PONV). Both drugs have shown effectiveness in monotherapy, however, there is evidence that patients at high risk of emesis can benefit from their combination [102, 103]. Since both droperidol and ondansetron are known to prolong QT interval, it can be anticipated that the clinical effect of combined therapy may be modified by drug interactions and result in the increased risk of proarrhythmia. Two studies considering the effects of droperidol and ondansetron (alone and in combination) on QT interval duration have been identified [104, 105]. Both studies led to conclusion that arrhythmia risk for drug combination is not higher when compared with both antiemetics administered alone.

Ondansetron electrophysiological safety was also studied in combination with sevoflurane [106].

The results of this study indicated that despite of significant QTc prolongation by sevoflurane and enhancement of this effect by ondansetron the dispersion of ventricular repolarization is not affected and drug combination may be clinically safe. However, an additional risk factors assessment before administration and careful ECG monitoring was advised.

QT prolongations precipitated by droperidol and "blackbox" warning issued by FDA on possible ventricular arrhythmias associated with droperidol administration led to reduction of its use and search for compound sharing its antiemetic activity but with better safety profile. Two of the considered droperidol substitutes, found to have an effect on PONV (haloperidol and midazolam), were assessed for efficacy and safety in combination with dexamethasone. No significant QTc changes were found while the incidence of PONV was reduced $[107,108]$.

\section{Psychotropic drugs}

Polypharmacy involving psychotropic drug combinations is common despite the lack of evidence of its efficacy and safety [109]. The electrophysiological effects of psychotropic drugs used in monotherapy have been studied extensively, however the influence of combined therapy on QTc was not as widely investigated.

In the retrospective study, Correl and colleagues investigated the risk of QTc prolongation for patients on monoand polytherapy with antipsychotics [110]. Patients treated concurrently with two atypical antipsychotics were matched with controls on monotherapy for sex and antipsychotic agent. The average QTc dispersion observed in combination therapy group was similar among patients treated with monotherapy, despite the fact that patients receiving antipsychotic polytherapy were administered significantly higher chlorpromazine-equivalent dosages. These results suggest that polytherapy with two atypical antipsychotics, in moderate doses, does not involve significant QTc prolongation and challenge the common assumption about dose-dependence of QTc prolongation for antipsychotics $[111,112]$. Similarly, Sala with coworkers in their retrospective study did not find any significant increase in the average QTc interval following antipsychotic monotherapy (haloperidol, olanzapine, risperidone or clozapine) in female patients. There was, however, meaningful QTc prolongation noted when antidepressants (escitalopram, citalopram, mirtazapine, paroxetine, sertraline, fluvoxamine, venlafaxine, clomipramine) or lithium were administered concomitantly 
[113]. The average QTc interval and QTc change after treatment was $421 \pm 20 \mathrm{~ms}$ and $-1 \mathrm{~ms}$ in the monotherapy group and $438 \pm 30 \mathrm{~ms}$ and $24 \mathrm{~ms}$ in the polytherapy group. Moreover, there was a significant difference between the treatment groups in the number of patients who had QTc values above $450 \mathrm{~ms}$, seven patients (38\%) in the polytherapy group vs. one patient (7\%) in the monotherapy. Antidepressant agents investigated in the study are known to have a mild inhibitory activity on drug-metabolizing enzymes from CYP family, however, in this study PK interactions did not seem to contribute substantially to QTc prolongation in the group with combined therapy as serum levels of antipsychotics were not higher in this group compared to monotherapy patients. In the view of the results authors suggest an accurate monitoring of the QTc before and after the treatment, especially for those receiving multiple psychoactive agents with QT prolonging propensity.

Some of the drug combinations analyzed in poly- and monotherapy were also investigated more thoroughly in other studies [96, 114-117]. Drug pairs studied included other psychoactive agents commonly used together with antipsychotics and with metabolic inhibitors, administration of which is likely to coincide with psychoactive compounds (itraconazole, ketoconazole, clarithromycin). The studied DDIs did not result in as dramatic changes of PK and PD as in case of terfenadine and ketoconazole, yet complex and individualized risk to benefit ratio evaluation is advised prior to prescription of any antipsychotic.

\section{Agents used in drug dependence therapy}

Racemic methadone is used in maintenance therapy of opiate addicts. Both S- and R-form of methadone inhibit the cardiac potassium channel hERG (S-methadone is more potent blocker) [118], which may increase heart risk. Indeed, the incidences of torsades de pointes arrhythmia in methadone-treated patients have been reported [119]. Drugs tested for potential increase in the cardiac risk of methadone include voriconazole, which can be administered concomitantly in case of serious fungal infections occurring in addicts [120]. Administration of lofexidine, an agent used inter alia for opioid detoxification, may coincide with methadone as it supports transition from methadone to buprenorphine [119]. No significant changes in QTc length were observed neither in patients receiving only methadone nor in patients on drug combination.

Another agent used in opioid dependence treatment is buprenorphine, which can be also given concomitantly with naloxone [121, 122]. Although buprenorphine is said to inhibit IKr potassium current only in concentrations higher than therapeutic, being CYP 3A4 substrate it is prone to interact and consequently to put patients at risk of QT interval prolongation. Electrophysiological consequences of CYP 3A4 inhibition induced by antiretrovirals with range of inhibitory potential were evaluated and proved this mechanism to be out of clinical importance in terms of QTc interval prolongation.

Modafinil is considered as a potential treatment for cocaine addiction, thus the co-administration of both compounds to cocaine addicts seemed possible. While cocaine is said to prolong QT interval and the potential enhancement of that effect by modafinil is probable, a study assessing ECG changes in case of concomitant administration of these agents was designed [123]. In general, this group of drugs is not associated with significant QT prolongation risk, even in combinations with agents which administration likely coincides.

\section{Antimalarials}

To date malaria still claims the lives of people in tropical countries. Chloroquine that used to be antimalarial of choice is no longer as highly effective as initially [124]. However, it may be still used to potentiate the curative effect of other drugs. The drugs combinations investigated for their pro-arrhythmic potential include i.e. primaquine plus chloroquine, tafenoquine and chloroquine, amodiaquine and halofantrine, halofantrine and mefloquine, atovaquone and proguanil, artesunate and mefloquine, artemether and lumefantrine, dihydroartemisinin and dihydroartemisinin/mefloquine combination, dihydroartemisinin and piperaquine what gives a flavor of its potential clinical meaning with regard to the cardiac safety [125-137]. Despite substantial changes in drugs PK observed in some of the studies in a majority of cases there was no correlation between plasma concentration of drugs and electrophysiological effects and no clinically important QTc interval prolongation cases were found. Cardiac safety of antimalarials was also confirmed in a study by Lefèvre and colleagues [138] where despite the artemether/lumefantrine pharmacokinetic changes caused by ketoconazole, ECG parameters, including QTc interval, did not exceeded normal limits in either of treatment groups.

\section{Varia}

Several interaction studies focusing on the cardiac safety of drugs from other therapeutic groups were identified. They concern anesthetics given concomitantly with anticholinergics [139], neuromuscular blockers and their antidotes [140, 141], medications used for treatment of asthma and chronic obstructive pulmonary disease (fluticasone furoate/vilanterol) [142], combination of antihypertensive drugs (losartan and spironolactone) [143] and others $[29,142,144]$.

\section{Discussion and conclusions}

Fatal in consequences terfenadine - ketoconazole case with cardiac related deaths played a significant role in recognition of the clinical role of drug-drug interactions 
and their desirable and undesirable consequences [145]. The pharmacokinetic DDI studies are now part of the drug screening procedure for multiple reasons which include, but are not limited to, assessment of necessity of a dosage adjustment, need for additional therapeutic monitoring, or due to the safety reasons when certain drugs should be contraindicated for concomitant use for the sake of patient safety.

The available guidance focuses on the PK drug interaction studies where the blood or tissue concentrations are modified by the disruption of drug's absorption, distribution, metabolism, and excretion processes triggered by the interacting compounds [146]. It was not assessed in the current study as it needs separate, specifically designed analysis but it is not surprising that majority of the above mentioned drugs are metabolized by CYP 3A4 and CYP 2D6 [147]. It opens the possibility to undergo the metabolic interaction (inhibition or induction) resulting in the clinical effect modification. Therefore this can be considered as a drug related risk factor, similarly to the drug transporters (e.g. P-gp) affinity, protein binding, high lipophilicity and consequent significant heart tissue penetration [148-150]. Assessment of the pharmacodynamic effects of the drug interactions is much more challenging due to the significant diversity in the endpoints which should be analyzed depending on the clinical effect. Pharmacokinetic parameters modification including $\mathrm{AUC}$ and $\mathrm{C}_{\max }$ are relatively easy to assess as compared with the pharmacodynamic endpoints for which the clinical surrogates are often imperfect if they exist at all. Another challenge comes with the results variability, which results from exposure variability and factors specific for the observed parameter, so the interacting drugs add additional level of complexity to already complex situation. Analyzing trials' results for evaluation of DDIs role in proarrhthmia risk brings additional hurdles. This is mainly due to the differences in study design e.g. single dose or multiple dose protocol, study duration, population age, sex, or ethnicity and methods of evaluation of raw data used to generate reported endpoints. First, there are several methods for QT interval length correction for heart rate, Bazzet, Fridericia or individual or population-based, just to mention those most commonly used, without individual data it is impossible to compare the results between the studies [151]. Second, the reported endpoint can be substantially influenced by the applied method of comparison. Drug-triggered QTc changes may be referred to placebo control or to the baseline QT values.

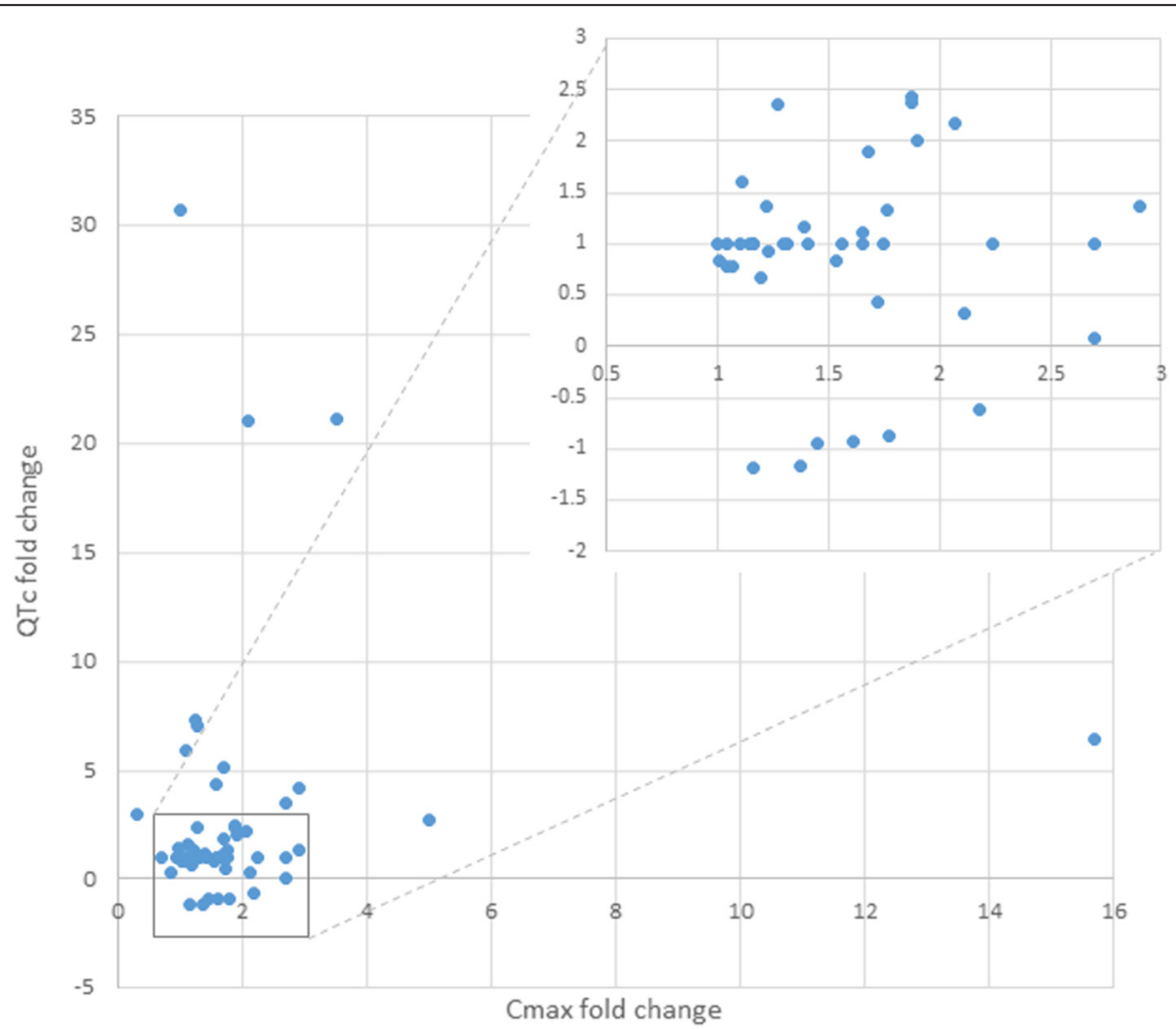

Fig. 2 PK fold change (Cmax) vs. PD fold change (QTc). Fold change $=C_{\max }$ Combination/ $C_{\max }$ Drug and $\Delta Q T c C o m b i n a t i o n / \Delta Q T c D r u g ; ~ N e g a t i v e$ values of QTc fold change represent QTc interval change for negative $\Delta$ QTc values as compared to baseline (QTc shortening for single drug, as well as for the combination) 
Baseline measurement can be defined as QTc interval length at single point registration (rarely reported time of a day) or mean from several time points. Similarly, reported QTc values were derived in various way, e.g. maximal and/ or average of individual QTc values at defined time point after drug application, maximal and/or average of individual QTc values over several hours following last day of drug application [152]. Finally, in some cases, reader can be confused about the true value of the reported endpoints, while there are different values reported in the tables and in the text or graph. Nevertheless, DDIs' role was clearly shown in the retrospective analyses done by multiple authors. Haugaa and colleagues correlated QT-related mortality with multiple factors and found that number of QT-prolonging medications was a significant predictor of death [153]. Similar results were observed in DeBruin study where the risk of cardiac arrest was more pronounced in patients receiving more than 1 QT-prolonging drug simultaneously [154]. The collation of studies identified for this overview suggest the need for assessment of an additional risk factors for proarrhythmia as there are examples where pharmacokinetic changes do not contribute substantially to QTc interval prolongation and plasma concentrations are not correlated with observed electrophysiological effects (Fig. 2). Careful ECG monitoring before administration of drug combinations with anticipated QT prolongation, especially with concomitant risk factors, has been suggested in many of the reports. However, there are some concerns on monitoring cost effectiveness [155].

Moreover, it can be safely assumed that the list of studies presented in the current publication covers just small number of potential combinations and additionally the incidence of the life threatening situations is low therefore it is quite likely that clinical trials with their current methodology cannot offer the expected power. Also, in case of elderly, multimorbid, or critically ill patients undergoing polytherapy the DDI risk is substantially increased, while such scenario testing is barely feasible, if not impossible at all and can be only analyzed retrospectively [156]. One of the possible ways of thorough data analysis is a traditional "top-down" PK/PD modeling and simulation (M\&S). In such approach empirical or descriptive models are utilized to describe the linkage between drug concentration and observed clinical response including cardiovascular biomarkers [157]. There are multiple examples of studies utilizing such approach for DDI assessment [158], although there are just few where PK/PD type of analysis was utilized for the assessment of QT modification triggered by the combination of drugs [159]. There are examples of successful implementation of nonlinear mixed-effects PK/PD models and Bayesian methods. Such approach can be especially useful when there is either limited or noised dataset. Prior distributions for the model parameters derived from previous single drug studies can improve predictivity and model quality [160].
It all suggests the need for a system of early prediction of the potential DDI clinical consequences. To the authors' best knowledge there is no established in vitro methodology offering such possibilities therefore potential solution lays in the proper use of the in silico based methods. This proposition can be supported by the recent wide incorporation of the in silico realized in vitro - in vivo extrapolation approach to the assessment of the clinical role of drug - drug interactions [161, 162]. Recently discussed drug cardiac safety assessment paradigm change includes wide use of mathematical models of human heart cells. This fact allows us to suggest that after proper validation such methods could be also applied for the fast and costeffective DDI consequences assessment which cannot be done in the traditional way due to the multiple obstacles.

\section{Additional file}

Additional file 1: Table S1. Characteristics of clinical trials assessing electrophysiological consequences of drug-drug interactions. (DOC $292 \mathrm{~kb}$ )

\section{Abbreviations}

AUC: Area under the plasma drug concentration-time curve; $C_{\text {max }}$ : Maximal plasma concentration; DDI: Drug-drug interaction; ECG: Electrocardiogram; AERS: Adverse Event Reporting System; ICH: International Conference on Harmonization; LQTS: Long QT syndrome; PD: Pharmacodynamics; PK: Pharmacokinetics; QTc: QT interval corrected for the heart rate; TdP: Torsades de pointes.

\section{Competing interests}

SP is an employee of Simcyp Ltd.

\section{Authors' contributions}

BW designed the study, collected information, analyzed and interpreted the data, drafted the manuscript; ZT collected information, analyzed the data, drafted the manuscript; GW collected information, analyzed the data, drafted the manuscript; SP analyzed and interpreted the data, drafted the manuscript. All authors read and approved the final manuscript.

\section{Acknowledgement}

This work was supported by Polish National Science Center [DEC-2013/11/D/ NZ7/01583].

\section{Author details \\ ${ }^{1}$ Unit of Pharmacoepidemiology and Pharmacoeconomics, Department of Social Pharmacy, Faculty of Pharmacy, Jagiellonian University Medical College, Medyczna 9 Street, 30-688 Krakow, Poland. ²Department of Pharmaceutical Technology and Biopharmaceutics, Faculty of Pharmacy, Medical College, Jagiellonian University, Medyczna 9 Street, 30-688 Kraków, Poland. ${ }^{3}$ Simcyp Ltd. (part of Certara), Blades Enterprise Centre, S2 4SU Sheffield, UK.}

Received: 19 November 2015 Accepted: 15 February 2016 Published online: 10 March 2016

\section{References}

1. Ferri N, Siegl P, Corsini A, Herrmann J, Lerman A, Benghozi R. Drug attrition during pre-clinical and clinical development: understanding and managing drug-induced cardiotoxicity. Pharmacol Ther. 2013;138:470-84.

2. Piccini JP, Whellan DJ, Berridge BR, et al. Current challenges in the evaluation of cardiac safety during drug development: Translational medicine meets the critical path initiative. Am Heart J. 2009;158:317-26. 
3. Redfern WS, Ewart L, Hammond TG, et al. Impact and frequency of different toxicities throughout pharmaceutical life cycle. Toxicologist. 2010;51:1081.

4. Force T, Kolaja KL. Cardiotoxicity of kinase inhibitors: The prediction and translation of preclinical models to clinical outcomes. Nat Rev Drug Discov. 2011;10:111-26.

5. Mellor HR, Bell AR, Valentin JP, Roberts RR. Cardiotoxicity associated with targeting kinase pathways in cancer. Toxicol Sci. 2011;120:14-32.

6. Laverty H, Benson C, Cartwright E, et al. How can we improve our understanding of cardiovascular safety liabilities to develop safer medicines? Br J Pharmacol. 2011;163:675-93.

7. Wenckebach K. Cinchona derivatives in the treatment of heart disorders. J Am Med Assoc. 1923:81:472-4

8. Selzer A, Wray HW. Quinidine syncope. paroxysmal ventricular fibrillation occurring during treatment of chronic atrial arrhythmias. Circulation. 1964; 30:17-26.

9. Dessertenne F. La tachycardie ventriculaire a deux foyers opposes variables. Arch Mal Coeur. 1966:59:263-72.

10. Sager PT, Gintant G, Turner JR, Pettit S, Stockbridge N. Rechanneling the cardiac proarrhythmia safety paradigm: A meeting report from the cardiac safety research consortium. Am Heart J. 2014;167:292-300.

11. Lee KS. Ibutilide, a new compound with potent class III antiarrhythmic activity, activates a slow inward na + current in guinea pig ventricular cells. J Pharmacol Exp Ther. 1992;262:99-108

12. January $C T$, Riddle JM. Early afterdepolarizations: Mechanism of induction and block. A role for L-type Ca2+ current. Circ Res. 1989;64:977-90.

13. Szabo B, Sweidan R, Rajagopalan CV, Lazzara R. Role of na : Ca2 exchange current in cs Induced early afterdepolarizations in purkinje fibers. J Cardiovasc Electrophysiol. 1994;5:933-44.

14. Roden DM, Lazzara R, Rosen M, Schwartz PJ, Towbin J, Vincent GM. Multiple mechanisms in the long-QT syndrome. current knowledge, gaps, and future directions. the SADS foundation task force on LQTS. Circulation. 1996;94: 1996-2012.

15. Suessbrich H, Waldegger S, Lang F, Busch AE. Blockade of HERG channels expressed in xenopus oocytes by the histamine receptor antagonists terfenadine and astemizole. FEBS Lett. 1996;385:77-80.

16. Roy M, Dumaine R, Brown AM. HERG, a primary human ventricular target of the nonsedating antihistamine terfenadine. Circulation. 1996;94:817-23.

17. Brown AM. HERG block, QT liability and sudden cardiac death. Novartis Found Symp. 2005;266:118-31. discussion 131-5, 155-8.

18. Camm AJ, Malik M, Yap YG. Acquired long QT syndrome. Oxford: Blackwell; 2004.

19. Redfern WS, Carlsson L, Davis AS, et al. Relationships between preclinical cardiac electrophysiology, clinical QT interval prolongation and torsade de pointes for a broad range of drugs: Evidence for a provisional safety margin in drug development. Cardiovasc Res. 2003:58:32-45.

20. Hancox JC, McPate MJ, El Harchi A, Zhang YH. The hERG potassium channel and hERG screening for drug-induced torsades de pointes. Pharmacol Ther. 2008;119:118-32.

21. FDA. Tikosyn (dofetilide), NDA 20-931. risk evaluation and mitigation strategy document. 2013:NDA 20-931/S-007.

22. Heist EK, Ruskin JN. Contemporary reviews in cardiovascular medicine druginduced arrhythmia. Circulation. 2010;122:1426-35.

23. Wisniowska B, Mendyk A, Fijorek K, Polak S. Computer-based prediction of the drug proarrhythmic effect: Problems, issues, known and suspected challenges. Europace. 2014;16:724-35.

24. De Ponti F, Poluzzi E, Montanaro N, Ferguson J. QTc and psychotropic drugs. Lancet. 2000;356:75-6.

25. Curtis LH, Ostbye T, Sendersky V, et al. Prescription of QT-prolonging drugs in a cohort of about 5 million outpatients. Am J Med. 2003;114:135-41.

26. Boyce MJ, Baisley KJ, Warrington SJ. Pharmacokinetic interaction between domperidone and ketoconazole leads to QT prolongation in healthy volunteers: A randomized, placebo-controlled, double-blind, crossover study. Br J Clin Pharmacol. 2012;73:411-21.

27. Katoh $\mathrm{T}$, Saitoh $\mathrm{H}, \mathrm{Ohno} \mathrm{N}$, et al. Drug interaction between mosapride and erythromycin without electrocardiographic changes. Jpn Heart J. 2003;44: 225-34

28. van der Sijs H, Kowlesar R, Klootwijk AP, Nelwan SP, Vulto AG, van Gelder T. Clinically relevant QTc prolongation due to overridden drug-drug interaction alerts: A retrospective cohort study. Br J Clin Pharmacol. 2009;67:347-54.

29. Zeuli JD, Wilson JW, Estes LL. Effect of combined fluoroquinolone and azole use on QT prolongation in hematology patients. Antimicrob Agents Chemother. 2013;57:1121-7.
30. Shaffer D, Singer S, Korvick J, Honig P. Concomitant risk factors in reports of torsades de pointes associated with macrolide use: Review of the united states food and drug administration adverse event reporting system. Clin Infect Dis. 2002:35:197-200.

31. Nemeroff CB, Preskorn SH, DeVane CL. Antidepressant drug-drug interactions: Clinical relevance and risk management. CNS Spectr. 2007:12:1-16.

32. Hinder M. Pharmacodynamic drug-drug interactions. In: Vogel HG, Maas J, Gebauer A, editors. Drug discovery and evaluation: Methods in clinical pharmacology. Berlin: Springer Science \& Business Media; 2010. p. 367-76.

33. Tartini R, Kappenberger L, Steinbrunn W, Meyer UA. Dangerous interaction between amiodarone and quinidine. Lancet. 1982;1:1327-9.

34. FDA.Drug development and drug interactions: Table of substrates, inhibitors and inducers. Available from http:/uww.fda.gov/Drugs/DevelopmentApprovalProcess/ DevelopmentResources/DrugInteractionsLabeling/ucm093664.htm. Accessed June 20, 2015.

35. Theisen K, Scheininger M. Electrophysiological effects of quinidine alone and of the combination quinidine-verapamil on AV conduction in humans. Clin Cardiol. 1983;6:405-11.

36. Belz GG, Doering W, Munkes R, Matthews J. Interaction between digoxin and calcium antagonists and antiarrhythmic drugs. Clin Pharmacol Ther. 1983;33:410-7.

37. Zhou H, Anthony LB, Roden DM, Wood AJ. Quinidine reduces clearance of $(+)$ propranolol more than (-) propranolol through marked reduction in 4 hydroxylation. Clin Pharmacol Ther. 1990;47:686-93.

38. Funck Brentano C, Kroemer H, Pavlou H, Woosley R, Roden D. Genetically determined interaction between propafenone and low dose quinidine: Role of active metabolites in modulating net drug effect. Br J Clin Pharmacol. 1989;27:435-44.

39. Funck Brentano C, Becquemont L, Kroemer HK, et al. Variable disposition kinetics and electrocardiographic effects of flecainide during repeated dosing in humans: Contribution of genetic factors, dose dependent clearance, and interaction with amiodarone. Clin Pharmacol Ther. 1994;55:256-69.

40. Lim KS, Jang I, Kim B, et al. Changes in the QTC interval after administration of flecainide acetate, with and without coadministered paroxetine, in relation to cytochrome P450 2D6 genotype: Data from an open-label, two-period, singlesequence crossover study in healthy korean male subjects. Clin Ther. 2010;32: 659-66.

41. Lim KS, Cho J, Jang I, et al. Pharmacokinetic interaction of flecainide and paroxetine in relation to the CYP2D6* 10 allele in healthy korean subjects. Br J Clin Pharmacol. 2008;66:660-6.

42. Fenrich AL, Perry JC, Friedman RA. Flecainide and amiodarone: Combined therapy for refractory tachyarrhythmias in infancy. J Am Coll Cardiol. 1995; 25:1195-8.

43. Demolis J, Charransol A, Funck Brentano C, Jaillon P. Effects of a single oral dose of sparfloxacin on ventricular repolarization in healthy volunteers. $\mathrm{Br} J$ Clin Pharmacol. 1996:41:499-503.

44. Antman EM, Sbatine MS. Cardiovascular therapeutics: A companion to Braunwald's heart disease. Philadelphia: Elsevier Health Sciences; 2012.

45. Panitch HS, Thisted RA, Smith RA, et al. Randomized, controlled trial of dextromethorphan/quinidine for pseudobulbar affect in multiple sclerosis. Ann Neurol. 2006;59:780-7

46. Pioro EP, Brooks BR, Cummings J, et al. Dextromethorphan plus ultra Low Dose quinidine reduces pseudobulbar affect. Ann Neurol. 2010;68:693-702.

47. Brooks BR, Thisted RA, Appel SH, et al. Treatment of pseudobulbar affect in ALS with dextromethorphan/quinidine: A randomized trial. Neurology. 2004; 63:1364-70.

48. Schoedel KA, Pope LE, Sellers EM. Randomized open-label drug-drug interaction trial of dextromethorphan/quinidine and paroxetine in healthy volunteers. Clin Drug Investig. 2012;32:157-69.

49. Craft TM. Torsade de pointes after astemizole overdose. Br Med J (Clin Res Ed). 1986;292:660.

50. Simons F, Kesselman M, Giddins N, Pelech A, Simons K. Astemizole-induced torsade de pointes. Lancet. 1988:332:624.

51. Davies AJ, Harindra V, McEwan A, Ghose RR. Cardiotoxic effect with convulsions in terfenadine overdose. BMJ. 1989:298:325.

52. Monahan BP, Ferguson CL, Killeavy ES, Lloyd BK, Troy J, Cantilena LR. Torsades de pointes occurring in association with terfenadine use. JAMA. 1990;264:2788-90

53. Woosley RL, Chen Y, Freiman JP, Gillis RA. Mechanism of the cardiotoxic actions of terfenadine. JAMA. 1993;269:1532-6.

54. Yap YG, Camm AJ. Drug induced QT prolongation and torsades de pointes. Heart. 2003;89:1363-72. 
55. Honig PK, Woosley RL, Zamani K, Conner DP, Cantilena Jr LR. Changes in the pharmacokinetics and electrocardiographic pharmacodynamics of terfenadine with concomitant administration of erythromycin. Clin Pharmacol Ther. 1992:52:231-8.

56. Honig PK, Wortham DC, Zamani K, Conner DP, Mullin JC, Cantilena LR. Terfenadine-ketoconazole interaction. pharmacokinetic and electrocardiographic consequences. JAMA. 1993;269:1513-8.

57. Honig PK, Wortham DC, Zamani K, Cantilena LR. Comparison of the effect of the macrolide antibiotics erythromycin, clarithromycin and azithromycin on terfenadine steady-state pharmacokinetics and electrocardiographic parameters. Drug Investigation. 1994;7:148-56.

58. Gibbs MA, Thummel KE, Shen DD, Kunze KL. Inhibition of cytochrome P-450 3A (CYP3A) in human intestinal and liver microsomes: Comparison of ki values and impact of CYP3A5 expression. Drug Metab Dispos. 1999;27:180-7.

59. Honig PK, Wortham DC, Hull R, Zamani K, Smith JE, Cantilena LR. Itraconazole affects single-dose terfenadine pharmacokinetics and cardiac repolarization pharmacodynamics. J Clin Pharmacol. 1993;33:1201-6.

60. Honig PK, Wortham DC, Zamani K, Mullin JC, Conner DP, Cantilena LR. The effect of fluconazole on the steady state pharmacokinetics and electrocardiographic pharmacodynamics of terfenadine in humans. Clin Pharmacol Therapeut. 1993;53:630-6.

61. Harris S, Hilligoss DM, Colangelo PM, Eller M, Okerholm R. Azithromycin and terfenadine: Lack of drug interaction. Clin Pharmacol Ther. 1995;58:310-5.

62. Martin D, Zussman B, Everitt D, Benincosa L, Etheredge R, Jorkasky D. Paroxetine does not affect the cardiac safety and pharmacokinetics of terfenadine in healthy adult men. J Clin Psychopharmacol. 1997;17:451-9.

63. Bergstrom RF, Goldberg MJ, Cerimele BJ, Hatcher BL. Assessment of the potential for a pharmacokinetic interaction between fluoxetine and terfenadine. Clin Pharmacol Ther. 1997;62:643-51.

64. Abernethy DR, Barbey JT, Franc J, et al. Loratadine and terfenadine interaction with nefazodone: Both antihistamines are associated with QTC prolongation. Clin Pharmacol Ther. 2001;69:96-103.

65. von Moltke LL, Greenblatt DJ, Granda BW, et al. Nefazodone, metachlorophenylpiperazine, and their metabolites in vitro: Cytochromes mediating transformation, and P450-3A4 inhibitory actions. Psychopharmacology (Berl). 1999;145:113-22

66. Morganroth J, Hunt T, Dorr MB, Magner D, Talbot GH. The effect of terfenadine on the cardiac pharmacodynamics of sparfloxacin. Clin Ther. 1999;21:1514-24

67. Akhtar M, Saha N, Roy A, Pillai K. Effect of sparfloxacin and terfenadine combination on QT-intervals at various RR-intervals. Indian J Pharmacol. 2002;34:264-8.

68. Lu C, Li AP. Enzyme inhibition in drug discovery and development: The good and the bad. New Jersey: John Wiley \& Sons; 2010.

69. Kalliokoski A, Niemi M. Impact of OATP transporters on pharmacokinetics. $\mathrm{Br}$ J Pharmacol. 2009;158:693-705

70. Carlquist JF, Anderson JL. Pharmacogenetic mechanisms underlying unanticipated drug responses. Discov Med. 2011;11:469-78.

71. Kurata $Y$, leiri I, Kimura M, et al. Role of human MDR1 gene polymorphism in bioavailability and interaction of digoxin, a substrate of P-glycoprotein. Clin Pharmacol Ther. 2002;72:209-19.

72. Gupta S, Banfield C, Kantesaria B, et al. Pharmacokinetic and safety profile of desloratadine and fexofenadine when coadministered with azithromycin: A randomized, placebo-controlled, parallel-group study. Clin Ther. 2001:23:451-66.

73. Bachmann K, Sullivan TJ, Reese $J H$, et al. A study of the interaction between dirithromycin and astemizole in healthy adults. Am J Ther. 1997:4:73-9.

74. Lefebvre RA, Van Peer A, Woestenborghs R. Influence of itraconazole on the pharmacokinetics and electrocardiographic effects of astemizole. Br J Clin Pharmacol. 1997:43:319-22.

75. Brannan MD, Reidenberg P, Radwanski E, et al. Loratadine administered concomitantly with erythromycin: Pharmacokinetic and electrocardiographic evaluations. Clin Pharmacol Ther. 1995:58:269-78.

76. Chaikin P, Gillen MS, Malik M, Pentikis H, Rhodes GR, Roberts DJ. Coadministration of ketoconazole with $\mathrm{H} 1$-antagonists ebastine and loratadine in healthy subjects: Pharmacokinetic and pharmacodynamic effects. Br J Clin Pharmacol. 2005;59:346-54

77. Kosoglou T, Salfi M, Lim JM, Batra VK, Cayen MN, Affrime MB. Evaluation of the pharmacokinetics and electrocardiographic pharmacodynamics of loratadine with concomitant administration of ketoconazole or cimetidine. Br J Clin Pharmacol. 2000;50:581-9.
78. Carr RA, Edmonds A, Shi H, et al. Steady-state pharmacokinetics and electrocardiographic pharmacodynamics of clarithromycin and loratadine after individual or concomitant administration. Antimicrob Agents Chemother. 1998:42:1176-80.

79. Banfield C, Herron J, Keung A, Padhi D, Affrime M. Desloratadine has no clinically relevant electrocardiographic or pharmacodynamic interactions with ketoconazole. Clin Pharmacokinet. 2002;41 Suppl 1:37-44.

80. Banfield C, Hunt T, Reyderman L, Statkevich P, Padhi D, Affrime M. Lack of clinically relevant interaction between desloratadine and erythromycin. Clin Pharmacokinet. 2002;41 Suppl 1:29-35.

81. Affrime M, Banfield C, Glue P, Keung A, Herron J, Padhi D. 1128 desloratadine and ketoconazole: Pharmacokinetics and electrocardiographic pharmacodynamic effects. J Allergy Clin Immunol. 2000;105:S386.

82. Glue P, Banfield C, Affrime M, Statkevich P, Reyderman L, Padhi D. 1130 desloratadine and erythromycin: Pharmacokinetics and electrocardiographic pharmacodynamic effects. J Allergy Clin Immunol. 2000;105:S387.

83. Tyl B, Kabbaj M, Azzam S, et al. Lack of significant effect of bilastine administered at therapeutic and supratherapeutic doses and concomitantly with ketoconazole on ventricular repolarization: Results of a thorough QT study (TQTS) with QTconcentration analysis. J Clin Pharmacol. 2012;52:893-903.

84. World Health Organization. Cisapride. Pharmaceuticals: Restrictions in use and availability. essential drugs and medicines - quality assurance and safety of medicines health technology and pharmaceuticals. 2001;EDM/ QSM/2001.3.

85. Wysowski DK, Corken A, Gallo-Torres H, Talarico L, Rodriguez EM. Postmarketing reports of QT prolongation and ventricular arrhythmia in association with cisapride and food and drug administration regulatory actions. Am J Gastroenterol. 2001:96:1698-703.

86. Hennessy S, Leonard CE, Newcomb C, Kimmel SE, Bilker WB. Cisapride and ventricular arrhythmia. Br J Clin Pharmacol. 2008:66:375-85.

87. Bran S, Murray WA, Hirsch IB, Palmer JP. Long QT syndrome during high-dose cisapride. Arch Intern Med. 1995;155:765-8.

88. Lewin MB, Bryant RM, Fenrich AL, Grifka RG. Cisapride-induced long QT interval. J Pediatr. 1996;128:279-81.

89. Olsson S, Edwards IR. Tachycardia during cisapride treatment. BMJ. 1992;305: $748-9$

90. Kaumann AJ, Sanders L. 5-hydroxytryptamine causes rate-dependent arrhythmias through 5-HT4 receptors in human atrium: Facilitation by chronic $\beta$-adrenoceptor blockade. Naunyn Schmiedebergs Arch Pharmacol. 1994;349:331-7.

91. Wysowski DK, Bacsanyi J. Cisapride and fatal arrhythmia. N Engl J Med. 1996; 335:290-1.

92. van Haarst AD, Klooster GA v 't, van Gerven JM, et al. The influence of cisapride and clarithromycin on QT intervals in healthy volunteers. Clin Pharmacol Ther. 1998;64:542-6.

93. Zix JA, Geerdes-Fenge HF, Rau M, et al. Pharmacokinetics of sparfloxacin and interaction with cisapride and sucralfate. Antimicrob Agents Chemother. 1997; 41:1668-72.

94. Polak S, Wisniowska B, Glinka A, Polak M. Tox-database.net: A curated resource for data describing chemical triggered in vitro cardiac ion channels inhibition. BMC Pharmacol Toxicol. 2012;13:6,6511-13-6.

95. Zhao Q, Wojcik MA, Parier J, Pesco Koplowitz L. Influence of coadministration of fluoxetine on cisapride pharmacokinetics and QTc intervals in healthy volunteers. Pharmacotherapy. 2001:21:149-57.

96. Alderman J. Coadministration of sertraline with cisapride or pimozide: An open-label, nonrandomized examination of pharmacokinetics and corrected QT intervals in healthy adult volunteers. Clin Ther. 2005;27: 1050-63.

97. Hemeryck A, Belpaire FM. Selective serotonin reuptake inhibitors and cytochrome P-450 mediated drug-drug interactions: An update. Curr Drug Metab. 2002;3:13-37.

98. Sproule BA, Naranjo CA, Bremner KE, Hassan PC. Selective serotonin reuptake inhibitors and CNS drug interactions. Clin Pharmacokinet. 1997;33:454-71.

99. VandenBrink BM, Isoherranen $\mathrm{N}$. The role of metabolites in predicting drug-drug interactions: Focus on irreversible cytochrome P450 inhibition. Curr Opin Drug Discov Devel. 2010;13:66-77.

100. Robert $M$, Salva $M$, Segarra $R$, et al. The prokinetic cinitapride has no clinically relevant pharmacokinetic interaction and effect on QT during coadministration with ketoconazole. Drug Metab Dispos. 2007;35:1149-56.

101. Yoshida N, Ito T. Mosapride citrate (AS 4370), a new gastroproltinetic agent, is a partial 5 HT4 receptor agonist in the gut. Neurogastroenterol Motil. 1994;6:197-204 
102. Gan TJ, Meyer T, Apfel CC, et al. Consensus guidelines for managing postoperative nausea and vomiting. Anesth Analg. 2003;97:62-71.

103. Kovac AL. Meta-analysis of the use of rescue antiemetics following PONV prophylactic failure with 5-HT3 antagonist/dexamethasone versus singleagent therapies. Ann Pharmacother. 2006;40:873-87.

104. Chan MT, Choi KC, Gin T, et al. The additive interactions between ondansetron and droperidol for preventing postoperative nausea and vomiting. Anesth Analg. 2006;103:1155-62.

105. Charbit B, Alvarez JC, Dasque E, Abe E, Demolis JL, Funck-Brentano C. Droperidol and ondansetron-induced QT interval prolongation: A clinical drug interaction study. Anesthesiology. 2008;109:206-12.

106. Lee JH, Park YH, Kim JT, Kim CS, Kim HS. The effect of sevoflurane and ondansetron on QT interval and transmural dispersion of repolarization in children. Paediatr Anaesth. 2014;24:421-5.

107. Azim E, Ayman Abdul Shakour A. Combination of midazolam and dexamethasone in the prophylaxis of PONV is alternative of haloperidol in female patients undergoing gynecological laparoscopic operations. Ain Shams J Anesthesiol. 2009;2:1-9.

108. Chu CC, Shieh JP, Tzeng Jl, et al. The prophylactic effect of haloperidol plus dexamethasone on postoperative nausea and vomiting in patients undergoing laparoscopically assisted vaginal hysterectomy. Anesth Analg. 2008;106:1402-6.

109. Razzouk D, Kayo M, Sousa A, et al. The impact of antipsychotic polytherapy costs in the public health care in Sao Paulo, brazil. PLoS One. 2015;10: e0124791.

110. Correll CU, Frederickson AM, Figen V, et al. The QTc interval and its dispersion in patients receiving two atypical antipsychotics. Eur Arch Psychiatry Clin Neurosci. 2009;259:23-7.

111. Goren JL, Dinh TA. Psychotropics and sudden cardiac death. R I Med J (2013). 2013;96:38-41.

112. Wenzel-Seifert K, Wittmann M, Haen E. QTc prolongation by psychotropic drugs and the risk of torsade de pointes. Dtsch Arztebl Int. 2011;108:687-93.

113. Sala M, Vicentini A, Brambilla P, et al. QT interval prolongation related to psychoactive drug treatment: A comparison of monotherapy versus polytherapy. Ann Gen Psychiatry. 2005;4:1.

114. Harrigan EP, Miceli JJ, Anziano R, et al. A randomized evaluation of the effects of six antipsychotic agents on QTc, in the absence and presence of metabolic inhibition. J Clin Psychopharmacol. 2004;24:62-9.

115. Laughren T, Gordon M. FDA background on ZeldoxTM (ziprasidone hydrochloride capsules). FDA psychopharmacological drugs advisory committee. 2000;PDAC0700.M01.

116. Desta Z, Kerbusch T, Flockhart DA. Effect of clarithromycin on the pharmacokinetics and pharmacodynamics of pimozide in healthy poor and extensive metabolizers of cytochrome P450 2D6 (CYP2D6)*. Clin Pharmacol Therapeut. 1999:65:10-20.

117. Park JY, Shon JH, Kim KA, et al. Combined effects of itraconazole and CYP2D6*10 genetic polymorphism on the pharmacokinetics and pharmacodynamics of haloperidol in healthy subjects. J Clin Psychopharmacol. 2006;26:135-42.

118. Eap CB, Crettol S, Rougier J, et al. Stereoselective block of hERG channel by (S)-methadone and QT interval prolongation in CYP2B6 slow metabolizers. Clin Pharmacol Therapeut. 2007:81:719-28.

119. Schmittner J, Schroeder JR, Epstein DH, Krantz MJ, Eid NC, Preston KL. Electrocardiographic effects of lofexidine and methadone coadministration: Secondary findings from a safety study. Pharmacotherapy. 2009;29:495-502.

120. Liu P, Foster G, Labadie R, Somoza E, Sharma A. Pharmacokinetic interaction between voriconazole and methadone at steady state in patients on methadone therapy. Antimicrob Agents Chemother. 2007;51:110-8.

121. Baker JR, Best AM, Pade PA, McCance-Katz EF. Effect of buprenorphine and antiretroviral agents on the OT interval in opioid-dependent patients. Ann Pharmacother. 2006:40:392-6.

122. Baker JR, Heckman CJ, Best A, McCance-Katz EF. Lack of corrected QT (QTC) interval changes with buprenorphine and HIV therapeutics. 2005:PDAC0700.M01.

123. Dackis CA, Lynch KG, Yu E, et al. Modafinil and cocaine: A double-blind, placebocontrolled drug interaction study. Drug Alcohol Depend. 2003;70:29-37.

124. Laufer MK, Plowe CV. Withdrawing antimalarial drugs: Impact on parasite resistance and implications for malaria treatment policies. Drug Resist Updat. 2004;7:279-88.

125. Aina O, Akintnawa A, Akinyede $A$, et al. Comparative effect of dihydroartemisinin plus mefloquine combination and dihydroartemisinin alone on electrocardiogram in healthy nigerian volunteers. Int J Malar Trop Dis (IJMTD). 2010;5:202-7.
126. Bindschedler M, Lefevre G, Ezzet F, Schaeffer N, Meyer I, Thomsen M. Cardiac effects of co-artemether (artemether/lumefantrine) and mefloquine given alone or in combination to healthy volunteers. Eur J Clin Pharmacol. 2000;56:375-81.

127. Coyne P, Ajayi F, Harris J, Wiley T, Wortham D, Cantilena L. ECG pharmacodynamics and pharmacokinetics of halofantrine and mefloquine. Clin Pharmacol Therapeut. 1996;59:160.

128. Gupta RK, Van Vugt M, Paiphun L, et al. Short report: No evidence of cardiotoxicity of atovaquone-proguanil alone or in combination with artesunate. Am J Trop Med Hyg. 2005;73:267-8.

129. Karunajeewa H, Lim C, Hung TY, et al. Safety evaluation of fixed combination piperaquine plus dihydroartemisinin (artekin) in cambodian children and adults with malaria. Br J Clin Pharmacol. 2004:57:93-9.

130. Krudsood S, Looareesuwan S, Wilairatama $P$, et al. Effect of artesunate and mefloquine in combination on the fridericia corrected QT intervals in plasmodium falciparum infected adults from thailand. Trop Med Int Health. 2011;16:458-65.

131. Manning J, Vanachayangkul P, Lon C, et al. Randomized, double-blind, placebocontrolled clinical trial of a two-day regimen of dihydroartemisinin-piperaquine for malaria prevention halted for concern over prolonged corrected QT interval. Antimicrob Agents Chemother. 2014;58:6056-67.

132. Miller AK, Harrell E, Ye L, et al. Pharmacokinetic interactions and safety evaluations of coadministered tafenoquine and chloroquine in healthy subjects. Br J Clin Pharmacol. 2013;76:858-67.

133. Mytton OT, Ashley EA, Peto L, et al. Electrocardiographic safety evaluation of dihydroartemisinin piperaquine in the treatment of uncomplicated falciparum malaria. Am J Trop Med Hyg. 2007;77:447-50.

134. Nosten F, Ter Kuile F, Luxemburger C, et al. Cardiac effects of antimalarial treatment with halofantrine. Lancet. 1993;341:1054-6.

135. Omoruyi SI, Onyeji CO, Daniyan MO. Effects of prior administration of amodiaquine on the disposition of halofantrine in healthy volunteers. Ther Drug Monit. 2007;29:203-6.

136. Pukrittayakamee S, Tarning J, Jittamala P, et al. Pharmacokinetic interactions between primaquine and chloroquine. Antimicrob Agents Chemother. 2014;58:3354-9

137. Valecha N, Phyo AP, Mayxay M, et al. An open-label, randomised study of dihydroartemisinin-piperaquine versus artesunate-mefloquine for falciparum malaria in asia. PLoS One. 2010;5:e11880.

138. Lefevre G, Carpenter P, Souppart C, Schmidli H, McClean M, Stypinski D. Pharmacokinetics and electrocardiographic pharmacodynamics of artemetherlumefantrine (riamet) with concomitant administration of ketoconazole in healthy subjects. Br J Clin Pharmacol. 2002;54:485-92.

139. Saarnivaara L, Simola M. Effects of four anticholinesterase-anticholinergic combinations and tracheal extubation on QTc interval of the ECG, heart rate and arterial pressure. Acta Anaesthesiol Scand. 1998:42:460-3.

140. de Kam PJ, Grobara P, Dennie J, et al. Effect of sugammadex on QT/QTC interval prolongation when combined with QTc-prolonging sevoflurane or propofol anaesthesia. Clin Drug Investig. 2013;33:545-51.

141. De Kam P, Van Kuijk J, Prohn M, Thomsen T, Peeters P. Effects of sugammadex doses up to $32 \mathrm{mg} / \mathrm{kg}$ alone or in combination with rocuronium or vecuronium on QTC prolongation: A thorough QTC study. Clin Drug Investig. 2010;30:599-611.

142. Kempsford R, Allen A, Kelly K, Saggu P, Crim C. A repeat-dose thorough QT study of inhaled fluticasone furoate/vilanterol combination in healthy subjects. Br J Clin Pharmacol. 2014;77:466-79.

143. Shehab A, Elnour AA, Struthers AD. A randomised, controlled, doubleblind, cross-over pilot study assessing the effects of spironolactone, losartan and their combination on heart rate variability and QT dispersion in patients with chronic heart failure. Cardiovasc J Af. 2008; 19:292-6.

144. Darpo B, Ferber G, Zhou M, Sumeray M, Sager P. Lomitapide at supratherapeutic plasma levels does not prolong the qtc interval-results from a TQT study with moxifloxacin and ketoconazole. Ann Noninvasive Electrocardiol. 2013;18:577-89.

145. Huang SM, Strong JM, Zhang $L$, et al. New era in drug interaction evaluation: US food and drug administration update on CYP enzymes, transporters, and the guidance process. J Clin Pharmacol. 2008;48:662-70.

146. European Medicines Agency. Guideline on the investigation of drug interactions. 2010.

147. Indiana University, Department of Medicine. P450 Drug Interaction Table [Internet]. Available from: http://medicine.iupui.edu/clinpharm/ddis/main-table/.

148. Wienkers LC, Heath TG. Predicting in vivo drug interactions from in vitro drug discovery data. Nat Rev Drug Discov. 2005;4:825-33. 
149. König J, Müller F, Fromm MF. Transporters and drug-drug interactions: important determinants of drug disposition and effects. Pharmacol Rev. 2013;65:944-66

150. Hochman J, Tang C, Prueksaritanont T. Drug-drug interactions related to altered absorption and plasma protein binding: theoretical and regulatory considerations, and an industry perspective. J Pharm Sci. 2015;104:916-29.

151. Desai M, Li L, Desta Z, Malik M, Flockhart D. Variability of heart rate correction methods for the QT interval. Br J Clin Pharmacol. 2003;55:511-7.

152. Graff C. Choice of baseline in parallel thorough QT studies. Drug Saf. 2013; 36:389-92.

153. Haugaa KH, Bos JM, Tarrell RF, Morlan BW, Caraballo PJ, Ackerman MJ. Institution-wide QT alert system identifies patients with a high risk of mortality. Mayo Clin Proc. 2013;88:315-25.

154. De Bruin ML, Langendijk PN, Koopmans RP, Wilde AA, Leufkens HG, Hoes AW. In-hospital cardiac arrest is associated with use of non-antiarrhythmic QTc-prolonging drugs. Br J Clin Pharmacol. 2007;63:216-23.

155. Bouvy JC, Koopmanschap MA, Shah RR, Schellekens $H$. The cost-effectiveness of drug regulation: The example of thorough QT/QTc studies. Clin Pharmaco Ther. 2012;91:281-8.

156. Tisdale JE. Development and validation of a risk score to predict QT interval prolongation in hospitalized patients. Circ Cardiovasc Qual Outcomes. 2013; 6(4):479-87.

157. Collins TA, Bergenholm L, Abdulla T, et al. Modeling and simulation approaches for cardiovascular function and their role in safety assessment. CPT Pharmacometrics Syst Pharmacol. 2015;4(3):175-88.

158. Delavenne $X$, Laporte $S$, Demasles $S$, et al. Investigation of PK-PD drug-drug interaction between acenocoumarol and amoxicillin plus clavulanic acid. Fundam Clin Pharmacol. 2009;23(1):127-35.

159. Darpo B, Ferber $G$, Siegl P, et al. Evaluation of the QT effect of a combination of piperaquine and a novel anti-malarial drug candidate OZ439, for the treatment of uncomplicated malaria. Br J Clin Pharmacol. 2015;80(4):706-15.

160. Chain ASY, Dubois VFS, Danhof M, Sturkenboom MCJM, Della Pasqua O. Identifying the translational gap in the evaluation of drug-induced QTC interval prolongation. Br J Clin Pharmacol. 2013;76(5):708-24.

161. Shepard T, Scott G, Cole S, Nordmark A, Bouzom F. Physiologically based models in regulatory submissions: Output from the ABPI/MHRA forum on physiologically based modeling and simulation. CPT Pharmacometrics Syst Pharmacol. 2015;4:221-5.

162. Jones HM, Chen $Y$, Gibson $C$, et al. Physiologically based pharmacokinetic modeling in drug discovery and development: A pharmaceutical industry perspective. Clin Pharmacol Ther. 2015;97:247-62.

\section{Submit your next manuscript to BioMed Central and we will help you at every step:}

- We accept pre-submission inquiries

- Our selector tool helps you to find the most relevant journal

- We provide round the clock customer support

- Convenient online submission

- Thorough peer review

- Inclusion in PubMed and all major indexing services

- Maximum visibility for your research

Submit your manuscript at www.biomedcentral.com/submit

Biomed Central 